\title{
Value of measuring diurnal peak flow variability in the recognition of asthma: a study in general practice
}

\author{
H.A. Thiadens*, G.H. De Bock*+, F.W. Dekker*, J.A.N. Huysman*, J.C. Van Houwelingen\#, \\ M.P. Springer*, D.S. Postmas
}

Value of measuring diurnal peak flow variability in the recognition of asthma: a study in general practice. H.A. Thiadens, G.H. De Bock, F.W. Dekker, J.A.N. Huysman, J.C. Van Houwelingen, M.P. Springer, D.S. Postma. (OERS Journals Ltd 1998.

ABSTRACT: In this study we analysed the value of measuring diurnal peak flow variability (DPV) in general practice for diagnosing asthma or chronic obstructive pulmonary disease (COPD).

One hundred and eighty-two subjects, aged 18-75 yrs, with undiagnosed asthma or COPD, presenting with a persistent cough recorded a peak flow diary twice daily for 2 weeks. A diagnosis of asthma or COPD was based on the recurrence of airway symptoms in the past year accompanied by spirometric measurements and a provocative dose of methacholine causing a $20 \%$ fall in forced expiratory volume in one second. DPV was expressed as amplitude percentage highest of the day. Cut-off values of $15 \%$ and $20 \%$ (DPV15\%, DPV20\%) were employed and the number of days that these values were reached, was assessed. The influence of age, sex and pack-years smoking on DPV was analysed by logistic regression.

The $a$ priori probability to have asthma $(n=69)$ or COPD $(n=12)$ was $45 \%(81 / 182)$ and increased to $>70 \%$ with a DPV20\% for at least 3, and a DPV15\% for at least 4 days. Scoring formulas for asthma (DPV15\% (number of days present) + 4 (if female sex)) and for asthma and COPD combined (8× DPV15\% (number of days present) + 24 (if female sex) + pack-years smoking) predicted which subjects were at risk for having asthma (or COPD).

Simple formulas based on the number of days with diurnal peak flow variability at $15 \%$, female sex and pack-years can predict which patients with persistent cough are likely to have asthma or chronic obstructive pulmonary disease. Eur Respir J 1998; 12: 842-847.
Depts of $*$ General Practice, + Medical Decision Making, and \#Medical Statistics, Leiden University Medical Centre, Leiden, Dept of Clinical Epidemiology and Biostatistics, Academic Medical Centre Amsterdam University, Amsterdam, and $\S$ Dept of Lung Diseases, University Hospital Groningen, Groningen, The Netherlands

Correspondence: H.A. Thiadens

Dept of General Practice

Leiden University

P.O. Box 2088, 2301 CB Leiden

The Netherlands

Fax: 31715275325

Keywords: Asthma

chronic obstructive pulmonary disease diagnosis

diurnal peak flow variability

female sex

Received: July 301997

Accepted after revision May 211998

Supported by GlaxoWellcome BV, Medical Division, The Netherlands
It is often difficult for general practitioners (GPs) to diagnose patients at an early stage of asthma. Respiratory symptoms are not restricted to this syndrome and physical examination is not very specific. Guidelines, therefore, advocate additional tests and especially the use of peak flow meters [1-3]. This simple device enables the GP to assess airway obstruction and reversibility in the GP's surgery. Moreover, patients can take a peak flow meter home to measure their peak expiratory flow (PEF) several times a day over a certain period [4]. This may disclose an increased diurnal variability of PEF (DPV), which according to guidelines and consensus reports is a clear indication of bronchial lability, one of the essential aspects of asthma $[2,3]$.

In epidemiological studies, DPV is considered to be an important indicator of the presence of bronchial hyperresponsiveness $[5,6]$. In the inspection of patients' diary cards, it is recognized to be of value in assessing the severity of the asthma and changes in treatment programmes $[2,3,7]$. Some guidelines recommend using DPV, as obtained from the diary in the diagnostic phase, whenever in doubt $[1,3]$. GPs often have problems in diagnosing asthma, especially in patients with persistent cough or recurrent bronchial episodes. It is recommended to express
DPV by calculating the mean DPV over a certain period $[8,9]$. It is not likely, however, that GPs will calculate the mean DPV over an extended period, because of time restrictions. The international consensus states that a DPV $>15 \%$ for 1 day should be considered abnormal [2]. This may be correct for patients already known to have asthma, but it is not yet clear whether this cut-off is accurate for use in the diagnosis of asthma, nor is it known how many days of abnormal DPV are necessary for a correct asthma diagnosis. A further problem is a possible influence of factors such as age, sex and pack-years of smoking on DPV [10].

In general practice it is often impossible to distinguish between asthma and chronic obstructive pulmonary disease (COPD) at an early stage in one or two visits, especially in patients with persistent cough as the predominant symptom. Furthermore, some patients with COPD may also have asthmatic features such as wheeze. Therefore, it was decided to study the value of DPV, not only to diagnose asthma but also to diagnose asthma and COPD combined.

The aim of this study was to assess the value of measuring different levels of DPV over a two-week period for diagnosing asthma as well as asthma and COPD combined in 
subjects who presented to their GPs with symptoms of coughing for at least 2 weeks and who had not previously been diagnosed as having asthma or COPD. Different cutoff values of DPV were examined and the number of days on which these values exceeded normal values was investigated to assess which DPV patterns are most predictive of asthma. The influence of variables such as age, sex and pack-years of smoking on DPV was investigated.

\section{Patients and methods}

The study took place in a primary healthcare centre, situated in a coastal town with six GPs serving a catchment area of 12,000 persons. There are 8,450 registered patients, aged $18-75 \mathrm{yrs}$, whose mean age and sex distribution match the rest of the country. During 1994 all patients, 18-75 yrs of age, who consulted their GP with coughing that had lasted for at least 2 weeks, were invited to participate in the study [11]. They were excluded if they already had a diagnosis of asthma or COPD, if they were pregnant, or if they had a cardiovascular or concomitant pulmonary disease. After consulting their GP, patients were seen on the same day, and again 2 and 8 weeks later by the same doctor (J.A.N. Huysman). Data on respiratory symptoms were collected by a modified Medical Research Council (MRC) questionnaire at entry and at 8 weeks $[11$, 12]. Additional questions provided information about respiratory symptoms (wheeze, coughing and breathlessness) after contact with nonspecific stimuli such as smoke, dust, fog, exercise and specific allergens (house dust, hay, cats, dogs, birds, guinea-pigs and moulds). Patients were asked about current smoking behaviour and cumulative smoking exposure. For this purpose, pack-years of smoking were calculated as the product of years of smoking and mean cigarettes $\cdot$ day $^{-1}$ divided by 20 . At all three visits, the participants underwent physical examination and spirometry, accompanied by reversibility testing on the first and third visits. DPV was assessed in the two-week period between the first and the second visits. Informed consent was obtained from all participants and the Medical Ethics Committee of the University of Leiden approved the study.

\section{Ventilatory function}

Lung function was measured by a Microlab 3300 (Sensormedics, Rochester, UK) on all three occasions. Forced expiratory volume in one second (FEV1) and forced vital capacity (FVC) were measured until three reproducible recordings (a difference of $<5 \%$ ) were obtained, with the highest values being used for analyses. Reference values were those from the European Respiratory Society [13]. Reversibility was measured 15 min after inhalation of 400 $\mu \mathrm{g}$ salbutamol, administered through a spacer device (Volumatic; Glaxo, Zeist, The Netherlands). Reversibility was considered to be present if FEV1 improved by $\breve{S} 9 \%$ of the predictive value $[14,15]$.

Patients measured and recorded their PEF with a MiniWright meter (Clement Clarke International, London, UK) first thing in the morning and before the evening meal for a period of 14 days (between the first and second visits). A verbal standardized instruction was given to each subject. The highest of the three values of morning and evening measurements was used for analysis. The first day was excluded from analysis in order to reduce any learning effect [10]. Only diaries with at least 6 days of measurements were analysed.

On the second visit a methacholine provocation test was carried out [16]. Two-fold increments of methacholine chloride were administered from a starting dose of 0.06 $\mu \mathrm{mol}$ to a cumulative dose of $15.6 \mu \mathrm{mol}$. The challenge was discontinued if FEV1 fell by $\mathrm{S} 20 \%$ from the postsaline value or when a cumulative dose of $15.6 \mu \mathrm{mol}$ was reached. Males with an FEV1 $<1.5 \mathrm{~L}$ and females with an $\mathrm{FEV}_{1}<1.2 \mathrm{~L}$ were excluded from the challenge test.

A patient was considered to have asthma if there had been a previous period of respiratory symptoms for $>3$ weeks in the last year, accompanied by a provocative dose causing a $20 \%$ fall in FEV1 (PD20) ð15.6 $\mu$ mol methacholine and/or reversibility $\breve{S} 9 \%$ of predicted. COPD was considered if $\mathrm{FEV}_{1} \%$ pred was $<70 \%$ at baseline and $<75 \%$ after 2 and 8 weeks, reversibility after inhaling 400 $\mu \mathrm{g}$ salbutamol at baseline and after 8 weeks $<9 \%$ pred and improvement after 2 or 8 weeks in $\mathrm{FEV}_{1}<12 \%$ pred, either spontaneously or after medication (if prescribed by the GP) $[11,17]$.

\section{Statistical analysis}

Data for this study were analysed using SPSS 4.0 (SPSS, Chicago, IL, USA). Differences between subjects with and without asthma or COPD were analysed using Student's t-tests and nonparametric tests (Mann-Whitney) as appropriate. Differences in proportions were tested with Chisquared tests and, if appropriate, with Fisher exact tests. DPV was expressed as: (highest - lowest)/highest $\times 100 \%$ per day (amplitude \% highest). Based on these scores, the following parameters were calculated: 1) mean DPV (MDPV): the mean amplitude \% highest over the two-week period; 2) the MDPV, dichotomized for $10 \%$ (MDPV10) and 15\% (MDPV15); and 3) DPV15\% and DPV20\%, the number of days that the assessments of DPV were above $15 \%$ and $20 \%$ amplitude $\%$ highest, respectively. The numbers of subjects with and without asthma and COPD or only asthma were calculated for each score. Probabilities for each score of DPV15\%, DPV20\% and MDPV were estimated by logistic regression with asthma and asthma and COPD combined as the dependent variables. The number of subjects with a probability $>0.7$ of having asthma (and COPD) was calculated.

To determine the influence on DPV (DPV15\%, DPV20\% and MDPV) by factors known to influence the level of lung function, such as age, sex, height and pack-years of smoking, logistic regression was performed in a stepwise fashion with asthma, and asthma and COPD combined as the dependent variables. All variables with a p-value $<0.05$ were included. Based on B-values in the equation, scoring formulas were generated. Logistic regression was performed again to estimate the probabilities of asthma, and asthma and COPD combined for each score of the formulae. Results are presented as means and standard deviations (SD) if appropriate. 


\section{Results}

\section{Patients}

During the study period 221 subjects, 18-75 yrs of age, consulted their GP with persistent cough for at least 2 weeks. Two-hundred and five subjects (93\%) agreed to participate in the study. The first and second visits were attended by 192 subjects $(87 \%)$. Peak flow diaries were completed by 182 (95\%) subjects for at least 6 days (mean number of days' completion: 11.9 (SD 2.0)). The 10 individuals who did not complete their diary did not differ in age and sex from the participants. The characteristics of the remaining subjects $(n=182)$ are presented in table 1 . Sixty-nine subjects $(38 \%)$ were classified as having asthma and 12 subjects (7\%) as having COPD. Of the 182 subjects, $168(92 \%)$ were challenged with methacholine. A low ventilatory function precluded testing in 11 subjects and three subjects stopped during the challenge test owing to adverse effects. These 14 individuals did not differ in age and sex from the other participants.

\section{Diurnal variability in peak expiratory flow}

Subjects classified as having asthma or COPD had a significantly higher MDPV over a two-week period than coughing subjects without asthma or COPD: 6.8 (SD 3.6) versus $4.9 \%$ (2.8). Males had a significantly lower MDPV, $4.9 \%$ (SD 2.9) than females, 6.2\% (SD 3.4).

Table 2 shows the number of subjects with MDPV10, MDPV15, DPV15\% and DPV20\% for different numbers of days present, for asthma, and asthma and COPD combined. The probabilities of having asthma or COPD are shown for the different numbers of days. Forty-two per cent $(34 / 81)$ of the subjects with asthma or COPD and $43 \%(30 / 69)$ of the subjects with asthma did not have a single day of DPV15\%. The higher the number of days on which DPV15\% or DPV20\% was present, the higher the probability for having asthma or asthma and COPD combined. To reach a probability of having asthma or COPD

Table 1. - Patient characteristics $(n=182)$

\begin{tabular}{|c|c|c|}
\hline Age yrs & 44 & $(16)$ \\
\hline Males \% & 36 & \\
\hline Pack-years yrs & 8.6 & $(11.8)$ \\
\hline PD20 ð15.6 $\mu \mathrm{mol} \% *$ & 40.5 & \\
\hline PEF variability $\%^{+}$ & 5.5 & $(3.3)$ \\
\hline $\mathrm{FEV}_{1} \%$ pred & 91.7 & $(17.3)$ \\
\hline $\mathrm{FEV}_{1} / \mathrm{FVC} \%$ & 79.7 & $(8.8)$ \\
\hline$\Delta \mathrm{FEV}_{1} \%$ pred & 3.6 & $(4.5)$ \\
\hline$\Delta \mathrm{FEV} 1$ Š $9 \%$ pred $\mathrm{n}(\%)$ & 20 & (11) \\
\hline Symptoms last year $\mathrm{n}(\%)$ & 159 & (87) \\
\hline Asthma $\mathrm{n}(\%)$ & 69 & (38) \\
\hline COPD $\mathrm{n}(\%)$ & 12 & (7) \\
\hline
\end{tabular}

Values are means (SD). *: Percentage of 168 patients tested with methacholine chloride. +: Mean amplitude \% highest in subjects who completed peak expiratory flow (PEF) measurements for at least 6 days. $¥$ : Improvement in forced expiratory volume in one second (FEV1) after $400 \mu \mathrm{g}$ salbutamol, expressed as a percentage of predicted FEV1. PD20: provocative dose of methacholine causing a $20 \%$ fall in FEV1; FVC: forced vital capacity; COPD: chronic obstructive pulmonary disease.
Table 2. - Number of subjects with different number of days of high diurnal peak flow variability (DPV) stratified for asthma $(n=69)$, and asthma and chronic obstructive pulmonary disease (COPD) combined $(n=81)$ and the probabilities as obtained by logistic regression of having asthma (or COPD) for the number of days that DPV is present

\begin{tabular}{|c|c|c|c|c|c|c|}
\hline \multirow[t]{2}{*}{$\begin{array}{l}\text { Number of } \\
\text { days with } \\
\text { high variation }\end{array}$} & \multicolumn{2}{|c|}{$\begin{array}{l}\text { Asthma } \\
\text { present } \\
(n=170)\end{array}$} & \multirow[b]{2}{*}{ Probab. } & \multicolumn{2}{|c|}{$\begin{array}{c}\text { Asthma or } \\
\text { COPD present } \\
(n=182)\end{array}$} & \multirow[b]{2}{*}{ Probab. } \\
\hline & Yes & No & & Yes & No & \\
\hline \multicolumn{7}{|l|}{ DPV15\%* } \\
\hline 0 & 30 & 72 & 0.32 & 34 & 72 & 0.34 \\
\hline 1 & 13 & 13 & 0.40 & 13 & 13 & 0.44 \\
\hline 2 & 9 & 9 & 0.49 & 12 & 9 & 0.54 \\
\hline 3 & 3 & 4 & 0.58 & 4 & 4 & 0.63 \\
\hline 4 & 7 & 1 & 0.66 & 11 & 1 & 0.72 \\
\hline$>4$ & 7 & 2 & 0.83 & 7 & 2 & 0.88 \\
\hline \multicolumn{7}{|l|}{ DPV20\%* } \\
\hline 0 & 44 & 83 & 0.35 & 49 & 83 & 0.38 \\
\hline 1 & 9 & 11 & 0.47 & 12 & 11 & 0.51 \\
\hline 2 & 8 & 6 & 0.59 & 10 & 6 & 0.64 \\
\hline 3 & 4 & 0 & 0.70 & 5 & 0 & 0.76 \\
\hline$>3$ & 4 & 1 & 0.88 & 5 & 1 & 0.90 \\
\hline MDPV $10 \%+$ & 10 & 3 & 0.60 & 11 & 3 & 0.65 \\
\hline MDPV $15 \%^{+}$ & 2 & 1 & 0.78 & 2 & 1 & 0.83 \\
\hline
\end{tabular}

Probab.: probability; *: DPV15\%, DPV20\%: number of days that DPV was $>15 \%$ or $>20 \%$, respectively, during a two-week period. +: MDPV10\%, MDPV15\%: mean DPV with cut-off values of $10 \%$ and $15 \%$, respectively, during a two-week period.

of 0.70 , at least 4 days of DPV $15 \%$ or 3 days of DPV20\% was necessary, whereas a MDPV of at least $12 \%$ was needed (data not shown). In this way, 21, 11 and 14 subjects were identified, respectively. A MDPV of at least $15 \%$ was reached by only three subjects. Comparable results were obtained for asthma (without COPD).

Logistic regression revealed that, from the analysed expressions of DPV, DPV15\% contributed most significantly to asthma or COPD. Table 3 shows the B-values, SE and pvalues for DPV15\% female sex and pack-years of smoking for asthma, and asthma and COPD combined. These three variables contributed significantly to the presence of asthma or COPD, whereas pack-years of smoking was not significant in asthma (without COPD). Age and height did not contribute significantly to a diagnosis of asthma or COPD. Based on the B-values in table 3 , scoring formulae were generated giving a score to each of the significant variables when these were present: $($ asthma $)=$ number of days that DPV $15 \%$ is present +4 (if female sex) and $($ asthma or COPD) $=8 \times \mathrm{DPV} 15 \%$ (number of days that

Table 3. - Contribution of diurnal peak flow variability $>15 \%$ (DPV $15 \%$ ), sex and pack-years of smoking to a diagnosis of asthma, and asthma and chronic obstructive pulmonary disease (COPD) combined, as determined by regression analysis*

\begin{tabular}{|c|c|c|c|c|c|c|}
\hline \multirow[b]{2}{*}{ Variable } & \multicolumn{2}{|c|}{$\begin{array}{c}\text { Asthma or COPD } \\
(\mathrm{n}=182)\end{array}$} & \multirow[b]{2}{*}{ p-value } & \multicolumn{2}{|c|}{$\begin{array}{l}\text { Asthma only } \\
(n=170)\end{array}$} & \multirow[b]{2}{*}{ p-value } \\
\hline & B & SE & & $\mathrm{B}$ & SE & \\
\hline DPV15\% & 0.32 & 0.11 & 0.003 & 0.31 & 0.10 & 0.003 \\
\hline Pack-years & 0.0432 & 0.02 & 0.004 & 0.02 & 0.03 & 0.25 \\
\hline Sex & 1.0216 & 0.37 & 0.005 & 1.2 & 0.39 & 0.002 \\
\hline
\end{tabular}

*: Age and height did not reach significance and were removed from the equation. 


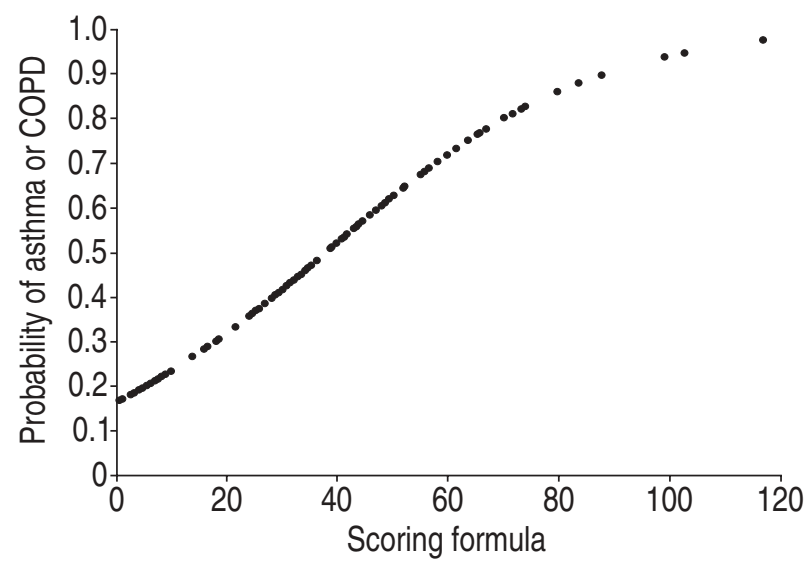

Fig. 1. - Relationship between scoring formula $(8 \times$ diurnal peak variability $>15 \%+24$ (if female sex) + pack-years smoking) and probability of having asthma of chronic obstructive pulmonary disease (COPD).

$\mathrm{DPV}_{15 \%}$ is present) +24 (if female sex) + pack-years of smoking. The scores for asthma and COPD combined ranged $0-117$ and for asthma $0-12$. Figure 1 shows the relationship between the scoring formula and the probability of having asthma and COPD combined.

Table 4 shows the scores from the formula for asthma and COPD combined, divided into 10 groups, the probabilities of having asthma or COPD and the number of subjects having these disorders for each score. The higher the score the higher the probability, e.g. a score between 60 and 70 corresponds to a probability of 0.75 for having asthma or COPD. Similar results were obtained for predicting asthma (table 5).

\section{Discussion}

The main finding from this study was that assessment of the number of days with abnormal DPV provides a diagnostic tool to identify individuals with asthma among undiagnosed patients attending a GP with a cough that has lasted for at least 2 weeks. Instead of calculating the MDPV over a full period of 2 weeks, DPV can be assessed more easily and even more accurately when screening

Table 4. - Scores derived from a scoring formula* to predict asthma or chronic obstructive pulmonary disease (COPD), divided into 10 groups, probabilities and the number of subjects with asthma or COPD for each score $(n=$ 182)

\begin{tabular}{cccc}
\hline Scores & $\begin{array}{c}\text { Probability of } \\
\text { having asthma } \\
\text { or COPD }\end{array}$ & $\begin{array}{c}\text { Number of } \\
\text { subjects with } \\
\text { asthma or COPD }\end{array}$ & $\begin{array}{c}\text { Number with } \\
\text { score }\end{array}$ \\
\hline $0-10$ & 0.18 & 8 & 37 \\
$10-20$ & 0.28 & 2 & 9 \\
$20-30$ & 0.36 & 16 & 51 \\
$30-40$ & 0.47 & 15 & 27 \\
$40-50$ & 0.57 & 11 & 20 \\
$50-60$ & 0.67 & 10 & 14 \\
$60-70$ & 0.75 & 8 & 11 \\
$70-80$ & 0.81 & 7 & 8 \\
$80-90$ & 0.88 & 2 & 2 \\
$90-117$ & 0.94 & 2 & 3 \\
\hline
\end{tabular}

*: Score (asthma or COPD) $=$ pack-years of smoking $+8 \times$ diurnal peak variability $>15 \%+24$ (if female sex).
Table 5. - Scores derived from a scoring formula* to predict asthma, the probabilities of having asthma and the number of subjects with asthma for each score

\begin{tabular}{lccc}
\hline Score & Probability & $\begin{array}{c}\text { Number of } \\
\text { subjects with } \\
\text { asthma }\end{array}$ & $\begin{array}{c}\text { Number of } \\
\text { subjects with } \\
\text { score }\end{array}$ \\
\hline 0 & 0.17 & 8 & 43 \\
1 & 0.22 & 1 & 5 \\
2 & 0.28 & 2 & 5 \\
3 & 0.34 & 0 & 2 \\
4 & 0.41 & 22 & 59 \\
5 & 0.49 & 13 & 22 \\
6 & 0.57 & 6 & 12 \\
7 & 0.64 & 4 & 6 \\
8 & 0.71 & 6 & 7 \\
9 & 0.77 & 1 & 2 \\
10 & 0.82 & 2 & 2 \\
11 & 0.86 & 1 & 2 \\
12 & 0.89 & 3 & 3 \\
\hline
\end{tabular}
$*:$ Score $($ asthma) $=$ diurnal peak variability $>15 \%+4$ (if
female sex). Subjects classified as having chronic obstructive pulmonary disease were excluded $(n=170)$.

for asthma when certain cut-off values are used in combination with the number of positive days. The a priori probability for having asthma in this study population was $38 \%$ (for asthma and COPD combined: $45 \%$ ). With a DPV15\% for at least 4 days, a DPV20\% for at least 3 days and a mean DPV $>10 \%$ as measured over a two-week period, the probability increased to values above 0.7 . Most subjects were identified when using DPV15\%. Notwithstanding this finding, 30 out of 69 patients with asthma (or 34 out of 81 patients when taking asthma and COPD combined) did not show any days with DPV15\%. Another important observation is that female sex and pack-years of smoking predicted asthma or COPD independently of DPV. With the exclusion of the COPD subjects, packyears of smoking did not contribute significantly. Scoring formulae based on numbers of days that DPV15\% was present, female sex and pack-years of smoking (if COPD subjects were included) were able to predict the patients at low or high risk of having asthma or COPD.

In most reports diurnal PEF variability is expressed as amplitude \% mean, i.e. (highest value - lowest value)/ mean value $\times 100 \%$. No significant difference was seen when comparing DPV expressed as amplitude \% highest and amplitude \% mean (data not shown). Therefore, DPV was only analysed as amplitude \% highest, because it is easier to calculate than amplitude $\%$ mean.

In this study, $15 \%$ and $20 \%$ variability in DPV were chosen for the following reasons. BRAND et al. [18], found a mean DPV of $15 \%$ in their long-term study of asthma and COPD outpatients. Several other authors have consi-dered the $20 \%$ cut-off as a useful test to identify asthma patients $[8,9,19]$.

One epidemiological study showed that a mean DPV $>10 \%$ was associated with at least three respiratory symptoms on a standardized questionnaire and lower airway calibre [20]. JAMISON and McKINLEY [21] observed that dur-ing a 12-day recording period, one single day with Š20\% variation (maximum - minimum PEF as \% of the minimum PEF of that day) best distinguished asthmatics from healthy individuals. However, the population in this study consisted of 123 asthmatics and 24 healthy subjects and 
was thus not comparable to patients in a general practice, who present with symptoms of cough, which may reflect either asthma, COPD or merely a common cold. We have developed a strategy by which to calculate the number of days with abnormal DPV. This reflects the short periods of abnormal variability, one of the important features of asthma, much more accurately. Although this strategy had similar probabilities to the mean DPV over a two-week period (e.g. DPV15\% for at least 4 days and MDPV >10), it is suggested that GPs use the number of days, since more subjects are identified in this way, which is of considerable clinical importance.

In this study group 69 subjects had asthma and only 12 had COPD. Therefore, the dataset was sufficient to address accurately analyses on asthma separately, but not on COPD separately. Whereas COPD is generally believed to have a lower DPV, lower probabilities were expected in testing the combination of asthma and COPD. However, the results were almost similar. This might result from the fact that only 12 subjects were classified as having COPD. Moreover, some of the patients classified as having COPD, still might have asthma since they were neither tested with a course of oral corticosteroids nor followed up to assess the full clinical picture. Since it is important for GPs to diagnose both diseases for future prospects, a scoring formula was composed to use in combined asthma and COPD. This may help GPs to determine when it is necessary to perform pulmonary function testing and/or to initiate a long-term follow-up, which is important for both diseases.

In this study, $>40 \%$ of the patients classified as having asthma did not show a single day of abnormal diurnal variation (DPV15\%). One explanation for the lack of sensitivity could be that the study group consisted of subjects with mild-to-moderate asthma or COPD, i.e. only nine (5\%) responded with a $20 \%$ fall in $\mathrm{FEV}_{1}$ during the first four inhaled doses of methacholine $(0.061-0.490 \mu \mathrm{mol}$ methacholine). Another explanation could be that the subjects only measured their PEF twice daily, thus resulting in a lower chance of finding higher amplitudes. Among GPs it is common practice to measure PEF only twice a day, as a result of considerations concerning feasibility, compliance and reliability [10]. Therefore, it was decided to ask the patients to measure PEF only twice a day, which resulted in a high compliance rate; only 10 people did not complete their diary for at least 6 days.

Although the influence of factors such as sex, age and pack-years on PEF variability is known from other studies, it is usually not taken into account in clinical practice [10]. The influence of female sex is surprising. There were more females than males with asthma in this study group and PEF variability was significantly higher in females than in males. The higher prevalence of asthma in females was found in another study performed in general practice and in a community study $[10,22]$, but other investigators did not find any differences between the sexes $[23,24]$. Therefore, it is unclear whether the findings in this study are only specific for the local population studied.

In conclusion, assessment of diurnal peak flow variability may be helpful in screening for asthma in subjects who have been coughing for at least 2 weeks, as frequently seen in general practice. A small number of days with high diurnal peak flow variability, measured over two-week period makes a diagnosis of asthma likely. More subjects are identified in this way than when using a mean diurnal peak flow variability over the full 2 weeks of measurement. Sex had a significant influence, in that males had a lower diurnal peak flow variability than females and required more days of high diurnal peak flow variability than females for asthma to be predicted accurately. A scoring formula using the number of days that a diurnal peak flow variability $>15 \%$ is present and female sex (and pack-years of smoking if asthma and chronic obstructive pulmonary disease are combined) will help general practitioners to select patients with a high probability of having asthma or chronic obstructive pulmonary disease, who should then be investigated further.

Acknowledgements: The authors acknowledge the participation in this study of the general practitioners and the patients from "Wantveld" and thank H. Bolk-Lucieer for correcting the text.

\section{References}

1. Dutch Guidelines on diagnosing asthma or COPD. Huisarts Wet 1992; 35: 430-436.

2. National Heart, Lung and Blood Institute. International Consensus Report on Diagnosis and Management of Asthma. Eur Respir J 1992; 5: 601-641.

3. National Institutes of Health, National Heart, Lung and Blood Institute. Global initiative for asthma. Global strategy for asthma management and prevention. NHLBI/ WHO Workshop Report. Publication number 95-3695, 1995.

4. Hargreave FE, Dolovich J, Newhouse MT. The assessment and treatment of asthma: a conference report. $J$ Allergy Clin Immunol 1990; 85: 1098-1110.

5. Higgins BG, Britton JR, Chinn S, Cooper S, Burney PGJ, Tattersfield AE. Comparison of bronchial reactivity and peak expiratory flow variability measurements for epidemiological studies. Am Rev Respir Dis 1992; 145: 588593.

6. Ryan G, Latimer KM, Dolovich J, Hargreave FE. Bronchial responsiveness to histamine: relationship to diurnal variation of peak flow rate, improvement after bronchodilator, and airway calibre. Thorax 1982; 37: 423-429.

7. Partridge MR. Patients self-assessment and treatment strategies for acute asthma. Res Clin Forums 1993; 15: 65-75.

8. Higgins BG, Britton JR, Chinn S, et al. The distribution of peak expiratory flow variability in a population sample. Am Rev Respir Dis 1989; 140: 1368-1372.

9. Quackenboss JJ, Lebowitz MD, Krzyzanowski M. The normal range of diurnal changes in peak expiratory flow rates: relationship to symptoms and respiratory disease. Am Rev Respir Dis 1991; 143: 323-330.

10. Boezen HM, Schouten JP, Postma DS, Rijcken B. Distribution of peak expiratory flow variability by age, gender and smoking habits in a random population sample aged 20-70. Eur Respir J 1994; 7: 1814-1820.

11. Thiadens HA, De Bock GH, Dekker FW, et al. Identifying asthma and chronic obstructive pulmonary disease in patients with persistent cough presenting to general practitioners: descriptive study. BMJ 1998; 316: 1286-1290.

12. Lende R van de, Orie NGM. The MRC-ECCS questionnaire on respiratory symptoms (use in epidemiology). Scand J Respir Dis 1972; 53: 218-226.

13. Quanjer PhH, Tammeling GJ, Cotes JE, Pedersen OF, 
Peslin R, Yernault J-C. Lung volumes and forced ventilatory flows. Eur Respir J 1993; 6: Suppl. 16, 5-40.

14. Dales RE, Spitzer WO, Toussignant P, Schechter M, Uissa S. Clinical interpretation of airway response to a bronchodilator. Am Rev Respir Dis 1988; 138: 317-320.

15. Brand PLP, Quanjer PH, Postma DS, Kerstjens HAM, Koeter GH, Dekhuijzen RPN and the Dutch CNSLD study group. Interpretation of bronchodilator response to bronchodilators in patients with obstructive airways disease. Thorax 1992; 47: 429-436.

16. Yan K, Salome C, Woolcock AJ. Rapid method for measurement of bronchial responsiveness. Thorax 1983; 38: 760-765.

17. Siafakas NM, Vermeire P, Pride NB, et al. Optimal assessment and management of chronic obstructive pulmonary disease (COPD). ERS-Consensus statement. Eur Respir J 1995; 8: 1398-1420.

18. Brand PLP, Postma DS, Kerstjens HAM, Koëter GH and the Dutch CNSLD Study Group. Relationship of airways hyperresponsiveness to respiratory symptoms and diurnal peak flow variation in patients with obstructive lung dis- ease. Am Rev Respir Dis 1991; 143: 323-330.

19. Hetzel MR, Clark TJH. Comparison of normal and asthmatic circadian rhythms in peak expiratory flow rate. Thorax 1980; 35: 732-738.

20. Boezen HM, Schouten JP, Postma DS, Rijcken B. Relation between respiratory symptoms, pulmonary function and peak flow variability in adults. Thorax 1995; 50: 121-126.

21. Jamison JP, McKinley RK. Validity of peak expiratory flow rate variability for the diagnosis of asthma. Clin Sci 1993; 85: 367-371.

22. Trigg CJ, Bennet JB, Sibbald B, Souza MF, Davies RJ. A general practice based survey of bronchial hyperresponsiveness and its relation to symptoms, sex, age, atopy, and smoking. Thorax 1990; 45: 866-872.

23. Woolcock AJ, Peat JK, Salome CM, et al. Prevalence of bronchial hyperresponsiveness and asthma in a rural adult population. Thorax 1987; 42: 361-368.

24. Burney PGJ, Britton JR, Chinn S, et al. Descriptive epidemiology of bronchial reactivity in an adult population: results from a community study. Thorax 1987 ; 42: 38-44. 